\title{
Malnutrition and the community-the social origins of deprivation
}

\section{By R. W. LonghuRst Graduate School of Arts \& Social Studies, University of Sussex, England*}

It is very tempting to say from the beginning that when it comes to reporting on research or impressions concerned with the socio-economic determinants of malnutrition there is not much new under the sun. A perusal of the first issue of Nutrition Planning, a new journal of abstracts which includes most of the important pieces written since 1970 on nutrition, its socio-economic determinants and proposed means for improvement, shows much good sense about what should be done and lots of jargon on nutrition planning, policy and its modelling. All too quickly the various situations under review seem to boil down to a problem of not enough income, or people with income not knowing the proper foods to eat or having enough time to prepare them. Despite the call for economic development, it seems that much of what has happened has caused or exacerbated malnutrition, suggesting a lack of 'fine tuning' or understanding of how changes in resource allocation can affect a malnourished child or the family which contains one.

This is the sort of information that doctors working in rural hospitals and clinics do assimilate but often do not articulate because they believe it is the business of the economist or planner to do so. Recent articles often in prestigious social science journals say little that most doctors with field experience do not know already, although they will serve to heighten awareness of the problems among uninformed audiences.

What can be said about the causation of malnutrition at community level that is 'new'? There is certainly a genuine methodological problem in collecting appropriate information to do research that goes beyond what has been published already; apart from the usual problems of sample size when marrying natural and social science methods, unprecedented monitoring is required of individuals in order to get an accurate picture of how at household or individual level the various aspects of nutrient intake, activity, body-weight changes, financial transactions and social contacts interweave. The work of Fox (1953) is probably still the only study that has attempted to relate intake to measured levels of energy expenditure throughout a full year; studies that have measured cash expenditure on food and other items, crop yields, labour input, debts and loans, farm produce sales and farm sizes require interviewing farmers two to three times a week for a year which has only rarely been done (see for example Haswell, 1953; Heyer, 1971; Norman, 1974); constant monitoring of indicators of nutritional status has not been widely done (one exception being the work carried out by the Medical Research Council

\footnotetext{
-Formerly, Research Associate, Department of Agricultural Economics \& Rural Sociology, Ahmadu Bello University, Zaria, Nigeria.
}

$\infty 029-6651 / 79 / 3813-2002$ sor.00 (c) 1979 The Nutrition Society 
in The Gambia) compared to one point or cross section studies. Understanding the determinants of malnutrition at community level requires an investigation that combines all three aspects (as well as some knowledge of social forces and personal motivations and attitudes) and this has yet to be published in any comprehensive manner. Therefore, despite the large mass of literature that has appeared on the socio-economics of malnutrition since it became popular among social scientists in the late I 960 s many gaps still exist in our knowledge.

This brief paper will discuss some of the determinants of malnutrition at the community level in rural areas from an agricultural point of view, which do not appear to have been widely researched. In particular it will focus on the cropping pattern. It is certainly recognized that other factors, notably infection and child care practices within the family, are also important. However, they cannot be immediately recognized as levers through which change can be brought within the community. Crop production, however, represents the livelihood of a large proportion of the rural population, provides a large proportion of their incomes and consumes much of their energy. Also most of the interventions from outside that do affect rural people are through agricultural projects.

The cropping pattern is also a focus with which to understand the allocation of resources in terms of 'energy flows' i.e. who (which family members of which families) consumes energy (and other nutrients), how much and when, and who spends energy, how much and when. Imbalances between energy expenditure and consumption at certain times of the year for certain family members will lead to changes in body energy stores. A negative balance will lead to a reduction in these stores and it is when this and other protective devices are driven beyond the limits of adaptability that PEM occurs. Some people in the community have to do certain tasks at certain times and cannot insulate themselves from this situation, others have the capacity to buy themselves out of such situations.

It is, therefore, hypothesized that a farm family's cropping pattern is a determinant of PEM and is also a variable that can be manipulated by policy; four aspects of this can be identified. Each of these will be discussed primarily in relation to the north of Nigeria where research has been carried out by this author and others (Norman, 1974; Simmons, 1976; Matlon, 1977). Information is still being analysed on some of these points and so some of the findings are not conclusive. These four components are:

(a) The nutrient content of what is grown will influence which nutrients are consumed.

In rural communities where families aim to be self sufficient, the basic staple which they grow will provide the majority of the nutrients. If this is a specific nutrient short, then so will be the diet. In a semi-arid area such as Sokoto, Zaria or Malumfashi in Northern Nigeria (with an annual rainfall of between 29 and 42 inches), the drought resistent grains of sorghum and millet are found, which form the basis of the diet; in these areas (where the growing season is between 150 and $180 \mathrm{~d}$ ) these two grains form about half of the cultivated acreage (Baker \& Norman, 1975). 
A comprehensive nutrition survey of the Zaria area (Simmons, 1976) showed that $73 \%$ of energy intake was derived from these cereals or their products. A community usually evolves its food habits and consumption on the basis of what is available locally. An increasing, though still small, proportion of the energy, is derived from bread. In ro-20 years this could become the main staple, invalidating this first sub hypothesis.

(b) Different cropping patterns will have different labour needs that will influence the allocation of time within the household and provide employment and hence incomes for landless labourers and their families.

In Moslem households, women of child bearing age do negligible amounts of farmwork and so this is not a constraint on their time. It is the obligation of the husband to provide all the food for the family and for the wife to care for the children and prepare the food. Once these joint obligations are met, both are free to carry out their own income earning work. Women process food for sale, for which the returns are very low, being motivated by their wish to build their savings. This situation is very different from that reported for Mwea in Kenya (Hanger \& Moris, 1973) where women have to grow as well as cook all food. More detailed examination of the resource allocation within the family is not in the terms of reference of this paper but it should be remembered that resource allocation may be more unequal within, rather than between, households; particularly with respect to nutrient intake.

As a general statement it can be said that there is no landless labourer class in the north of Nigeria. All who want to cultivate land can find it to rent, even though it may be of poor quality and some distance from a settlement. This is a situation very different from many parts of Asia and Africa where there are large numbers without access to land and who form the majority of the impoverished. They have been identified as being at greater nutritional risk than those with land (Chowdhury et al. 1978; Schofield, 1979). However, changes in the cropping pattern, either initiated from outside or generated from within the community, will have implications for labour inputs (i.e. energy expenditure) and hence employment. Efforts by the local agricultural extension staff to encourage the introduction of yellow maize in northern Nigeria are leading to a replacement of early millet in the cropping pattern so reducing the demand for labour.

(c) The seasonality characteristics of the cropping pattern will have particular implications for nutrition at certain times of the year as energy availability, incidence of infection and work needs interact.

Research findings presented at a recent conference organized jointly by the Institute of Development Studies and the London School of Hygiene and Tropical Medicine have indicated that a number of highly adverse factors (poor nutrition, heavy work load, infection, low food stocks, low wage rates, high food prices) can all combine at particular times of the year in such a way as to keep groups of people permanently impoverished (see especially Chambers, 1978). In particular heavy work needs interact with low energy availability (Longhurst \& Payne, 1978; Schofield, 1974). Although there are marked wet (April-September) and dry 
seasons in northern Nigeria there is a flow of harvested material available from August (early millet) through November (sorghum) to February (cotton). Therefore, problems of seasonality in this unimodal context would appear not to be as severe as in locations where there is a greater reliance on one staple. In this context the introduction of maize is a favourable aspect since it brings forward the first harvesting date by about ro $\mathrm{d}$.

(d) Access to land, labour and improved technology will influence the extent and nature of the marketable surplus and generation of incomes in the community.

It is clear that the richer families have preferential access to information and resources (fertilizer, pesticides, improved cultivation technology such as oxen and tractors). The reasons why inequality arises are complex and cannot be adequately summarized here (Hill (1972) provides one explanation). The richer farmers have inherited large amounts of land and a position in the community that gives them access to the information and resources needed to retain the patronage of others and to have access to income sources from outside the village. Therefore they can exert more control over their crops in the timing of operations and independence of erratic rainfall by their access to labour saving technology. Use of oxen for example, eliminates the bottleneck of first weeding by hand which so effectively determines the amount of land that can be cultivated, and although it does not reduce the total labour input per acre (since harvesting labour is increased) production is increased. All this serves to make more energy available to the family and enlarges the ratio of energy gained:energy expended.

The theme of this paper has been to examine the components of the cropping pattern in a rural community as being the variable most amenable to policy manipulation and thereby changing the levels of living in a community. Two questions remain: are differences in the cropping pattern of a family reflected in differences in the incidence of PEM in a community? And, despite all that has been said, is the cropping pattern a major determinant of the incidence of PEM? First the results are not yet available to show whether the children in the families of the farmers who are better off (because of what they inherit and their access to resources outside the community) suffer less malnutrition. It has been hypothesized that the reverse is true; that the richer, more commercialized farmers who plant a greater proportion of cash crops in fact have malnourished children. There is some evidence to support this (Hanger \& Moris, 1973; Jakobsen, 1978); in areas where there is a cash crop with a marketing board as its sole buying agent, the male head of the household who grows the crop receives cash as a lump sum at one time of the year, which is not usually applied to buying adequate food throughout the year. The situation is different in northern Nigeria since although there are cash crops (cotton and groundnuts) with a onetime selling point for cotton, farmers now perceive sorghum to be more profitable than either of these; with this crop they can choose the time of sale to a greater degree. Therefore the food-crop-cash-crop distinction is rather blurred. Poorer farmers undoubtedly have less choice about what to plant since they need a flow of harvested material from as early a point in time as possible, and have to labour on other farms in addition to 
their own in this pre-harvest period. How these aspects of the cropping pattern influence the health of children remains to be seen.

Finally, whatever the situation with respect to the expenditure and consumption of energy at the community level, malnutrition can still occur in apparently favourable conditions. Four very 'favourable' aspects (in terms of potential impact on nutrition) can be identified in the north of Nigeria compared to say, a stereotyped Asian situation. These are, plenty of land for crop cultivation, a staple which yields and stores well, a midday meal based on (pastoralists) milk and a food gifts system to help the impoverished. Yet the conventional indicators of child malnutrition show that there is a serious situation. For example, the infant mortality rate, calculated from a sample of pregnancy histories was 180/1000 births; by the age of 5 the number of deaths was 320/1000 births. Calculation of these rates from clinic attendance records in the same village showed figures of $204 / 1000$ and $365 / 1000$. Incidence of diagnosed 'severe' malnutrition at the same clinic varied between 7 and $7.9 \%$ in March-May and $2.8 \%$ in August-November (Pediatric Field Services, 1977). In a sample of eighty-five children in the area with unprotected water supplies $38 \%$ were less than $80 \%$ of the weight/height standard and in a sample of ninety-eight from protected water supplies the corresponding figure was $10.2 \%$ (Tomkins et al. 1978). A survey of hospital admissions in Zaria town showed that cases of malnutrition varied between $7 \%$ in January and $20 \%$ in June (Dossetor, 1975). These figures are admittedly aggregates in some cases and there are acknowledged problems in interpreting clinic and hospital admissions information. Nevertheless they are highly suggestive that despite a favourable agricultural situation malnutrition is still prevalent. Further analysis of the information will sharpen this judgment.

It appears that the 'background noise' of infection, poor hygiene and disease, particularly malaria, is still so great as to neutralize the favourable food production aspects mentioned above. It is disappointing to have to suggest that means to reduce malnutrition have to come from outside the community, e.g. more widespread provision of medicine or improved water supplies. Unequal social relations in the community, in this case, may not be the major cause and that easily engineered changes in the cropping pattern are not likely to improve malnutrition.

Relating malnutrition to specific aspects of the economic life of the community is difficult in view of the wide range of information that needs to be collected. It is suggested that analysis of the cropping pattern is a useful means of understanding the determinants of energy availability and consumption, their timing and distribution between families. It also provides the means through which change can be brought as so much human and economic activity revolves around crop production in rural areas. Aspects of the cropping pattern that are important are the nutrient content of crops grown, their labour needs and seasonality are discussed in relation to northern Nigeria. Access to yield increasing or labour saving inputs is also discussed. Several features of the cropping pattern indicate that it provides a highly favourable situation with respect to the availability of energy. However, when reviewing the information on the incidence of PEM in the 
area it appears that malnutrition is common and may not be related in its incidence to the cropping pattern. Improvement in the nutritional status of children may have to come, therefore, from outside interventions unrelated to the economic life of the community.

The author is grateful to the Department of Agricultural Economics and Rural Sociology and Department of Community Health at Ahmadu Bello University and to local officials in Malumfashi District for the assistance he received in carrying out the research.

\section{REFERENCES}

Baker, E. F. I. \& Norman, D. W. (1975). South E South East Asia Cropping Systems Network Workshop, IRRI Los Banos, Philippines.

Chambers, R. (1978). IDS/Ross Institute Conference, Seasonal Dimensions to Rural Poverty, University of Sussex.

Chowdhury, A. K., Alauddin, M., Huffman, S. \& Chen, L. C. (1978). IDS/Ross Institute Conference, Seasonal Dimensions to Rural Poverty, University of Sussex.

Dossetor, J. (1975). J. trop. Paediat. Env. Child Hith. Feb (Suppl) 16.

Fox, R. H. (1953). A Study of Energy Expenditure of Africans engaged in Various Rural Activities. PhD Thesis, University of London.

Hanger, J. \& Moris, J. (1973). In Mwea: An Irrigated Rice Settlement in Kenya. [R. Chambers and J. Moris editors]. Munich: Weltforum Verlag.

Haswell, M. R. (1953). Economics of Agriculture in a Savannah Village, Colonial Research Studies 8, London: HMSO.

Heyer, J. (1971). Fd Res. Inst. Stud. agric, econ. Trade Dez. 10, 55.

Hill, P. (1972). Rural Hausa, $A$ Village and a Setting, Cambridge: Cambridge University Press.

Jakobsen, O. (1978). Economic and Geographical Factors Influencing Child Malnutrition, BRALUP Res. paper 52, University of Dar-es-Salaam.

Longhurst, R. W. \& Payne, P. R. (1978). IDS/Ross Institute Conference, Seasonal Dimensions to Rural Pozerty, University of Sussex.

Mation, P. J. (1977). The Size Distribution, Structure and Determinants of Personal Income among Farmers in the North of Nigeria. PhD Thesis, Cornell University.

Norman, D. W. (1974). f. Dev. Stud. 11, 3.

Pediatric Field Services \& Training Unit (1977). A. Rep. Institute of Health Ahmadu Bello University, Nigeria.

Schofield, S. (1974). J. Der. Stud. 11, 22.

Schofield, S. (1979). Dez:elopment and the Problems of Village Nutrition, London: Croom Helm.

Simmons, E. B. (1976). Samaru Misc. Papers 55, Ahmadu Bello University, Nigeria.

Tomkins, A. M., Drasar, B. S., Bradley, A. K., Williamson, W. A. (1978). Proc. R. Soc. Trop. med. Hyg. 72, 3 . 